\title{
INVESTIGATION INTO WATER CONSUMPTION AND ITS INFLUENCE ON DEPRESSION, MEMORY PROBLEMS AND CONSTIPATION IN OLDER PERSONS
}

\author{
P.S. Tsindos, C. Itsiopoulos, A. Kouris-Blazos
}

\begin{abstract}
Objective: This study examines a possible relationship between plain water consumption, mild cognitive impairment, depression and constipation in a cohort of Greek-born Australians aged 65 and over. Design: A cross-sectional study using a semiquantitative food frequency and lifestyle questionnaire. Participants: We recruited 150 elderly Greek migrant volunteers who were born on Greek Mediterranean islands and collected detailed diet and lifestyle data using an established protocol used in the Mediterranean Islands Study (MEDIS) in Greece. Measurements: Water intake from plain water, beverages and foods was assessed using a validated food frequency questionnaire. Depression and memory were assessed using the validated Geriatric Depression Scale - Short version. Results: Mean water intake from all sources for all participants was $2871 \mathrm{~mL}(\mathrm{p}=0.010)$, water derived from foods was $1048 \mathrm{~mL}(\mathrm{p}=0.014)$, beverage intake other than plain water was $876 \mathrm{~mL}(\mathrm{p}<0.001)$ and plain water consumption was low with a mean of $947 \mathrm{~mL}(\mathrm{p}=0.001)$ per day. Those who reported as not depressed (GDS $<6)$ consumed $100 \mathrm{~mL}$ less total water from food and beverages than those who scored 6 or above and those who self-reported no constipation consumed nearly $300 \mathrm{~mL}$ more water in foods than those who self-reported being constipated. Conclusion: Results suggest that habitual low consumption of plain water $(<1000 \mathrm{~mL} /$ day) was not associated with constipation or self-reported mental-emotional disorders in this group. Water consumption from food was significantly higher in those with no constipation suggesting that consumption of water in food may be a significant factor in ensuring adequate water needs. Clinicians should consider water intake in food when assessing patient water intake.
\end{abstract}

Key words: Drinking, hydration, mild cognitive impairment, depression, constipation.

\section{Introduction}

For a number of years there has been a strong public movement arguing the need to drink two litres or eight glasses of plain water a day (1). Despite a lack of any tangible evidence, this argument has become commonplace with claims that failing to provide an abundance of water, puts the body in jeopardy $(2,3)$.

The view that water deprivation can lead to significant physical or mental dysfunction has not been well-researched. There is some evidence that poor consumption of plain water can cause an increased risk of cardiovascular disease, particularly in older men (4-7). As humans age, thirst diminishes and replenishment slows. (8) For older persons, this dysfunction can lead to a range of both physical and mental problems (6).

Researchers have noted that both depression and mild

Department of Rehabilitation, Nutrition and Sport, La Trobe University, Australia

Corresponding Author: P. Spero Tsindos, Department of Rehabilitation, Nutrition and Sport, La Trobe University, Bundoora, Victoria, 3086 Australia, Phone: +61 3 9244 6087, Fax: +61 35227 8130, Email: spero.tsindos@deakin.edu.au cognitive impairment (MCI) can occur concomitantly in older persons and that an inadequate water intake may initiate or exacerbate both conditions (9-12). MCI in particular can become evident and worsen when total body water (TBW) drops by 1-3\% (13-15). Szinnai, et al, (2005), investigated this relationship between water loss and MCI, with inconclusive results, suggesting in their conclusion that the withdrawal of caffeine may have attributed to some of the outcome (16). Other researchers have also argued that the evidence for this relationship is not definitive $(12,17)$. As a consequence, the evidence in support of a direct relationship between depression, $\mathrm{MCI}$ decline and hydration is not clear suggesting further research is required in this area. Further, there has been investigation into the relationship between diet and MCI, suggesting that a poor diet may have an influence in the progression of the condition (18).

Although there can be significant physiological problems associated with water deprivation in older persons, the research has not been forthcoming. When water intake is less than water output (hypohydration), there are physiological consequences. In a mild, chronic 
hypohydrated state, problems can include constipation and urinary tract infections $(19,20)$. Constipation in particular, is considered a common consequence of low water intake (19). It is estimated $15-20 \%$ of communityliving older persons suffer from constipation and a higher percentage in residential care (21). The significance of this disorder can vary depending a variety of factors, such as low fibre and on the extent of hypohydration.

Lastly, the determination of water requirement and whether it is adequate has been shown to be a difficult value to estimate. Although there has been a great deal of research into the problem of hypohydration, it has focussed on infants and children, those engaged in physical activities such as sport or within the military (22, 23). In relation to any effect on mental states, the focus has been on ambient temperature and water loss through sweating $(24,25)$. When considering effects of water intake on older persons, there has been little research conducted in this area when there is little physical activity and minimal exposure to high temperatures. (26) What has been investigated in this area is the effect of dehydration on older persons who have a diminished thirst response, a condition associated with ageing (27).

If a criterion for healthy living in older persons is consuming two litres of plain water a day, we would expect to see at least some of the above problems when less than two litres of plain water per day is consumed. Older Greek migrants in Australia have been extensively studied because of their mortality advantage over the Australian-born (28). Their desirable food habits have been linked to their lower mortality and CVD and diabetes risk (29). However, studies failed to investigate the role of water intake of older Greek-Australians with respect to health. Exploring the water intake of longlived older Greek-Australians may help further our understanding of water consumption and its effect on health.

\section{Method}

Using the dietary guidelines recommended by the Supreme Scientific Health Council of Greece (30), as a guide to estimating water requirements from a healthy Mediterranean diet model (from beverages and foods), we investigated whether failure to drink two litres of plain water a day may be associated with health implications for older persons. We therefore investigated the food and fluid intake of 139 older Greek Australians aged over 65 (as part of the epidemiological study MEDIS [MEDiterranean Islands Study]) to determine,

1. the relationship between plain water intake and mood, memory and bowel habits (plain water, in this instance is considered tap water, bottled water or filtered water with no flavourings).

2. methods by which water requirements can be estimated non-invasively.
The MEDIS-Australia study was conducted to compare health and lifestyle data of older Greek immigrants who were born on Greek Islands with that of the MEDIS study of the Harokopio University of Athens, Greece who investigated the health status of elderly Greek Islanders currently living on Greek islands. (31) The MEDIS-Australia study consisted of an extensive semiquantitative food frequency questionnaire (MEDIS-FFQ) and a detailed semi-structured lifestyle questionnaire (MEDIS-LQ). This study was reviewed and approved by the University Human Research and Ethics Committee in accordance with the National Health and Medical Research Council of Australia's National Statement on Ethical Conduct in Human Research (2007) .The study gathered information from a total of 179 participants, of which 139 completed the questionnaires fully and provided medical records. Although the MEDISAustralia data was originally designed to evaluate cardiovascular risk factors and establish a Mediterranean diet pattern score, we extracted relevant data to examine participant's self-reported food and water intake, depressive state (including the subjective perception of memory - a measure of cognition) and whether they suffered from constipation in association with hypohydration. Table 1, shows the overall demographics of the participants. The majority of participants were of Cretan or Cypriot origin (52 and 74 respectively) with the remainder from other islands, and one from the Greek mainland. There were more females than males with a mean age of 74 years. Compliance was high to a Mediterranean diet pattern, with only one participant scoring below 26 within a scale from zero to 55 . It has been shown that a score of 26 or more shows a strong adherence to a Mediterranean diet pattern (32).

A number of factors can make interpretation and determination of the diagnosis of depression difficult in older adults. Factors can include a concomitant illness, an absence of an obvious depressed mood, and social isolation (33). Evaluation of the mental health of the participants of the MEDIS-Australia Study was through the administration of the Geriatric Depression Scale Short version (GDS-S). The 30-item Geriatric Depression Scale has been used widely, and this short version (15 items) had been evaluated as a useful, quick alternative to the full version, which was thought to take too long to complete (34). The GDS-S also includes a question relating to memory. In the GDS-S a score of zero to five is considered normal, six to nine suggests mild depression, and a score of ten or more suggests moderate to severe depression. Question 10 of the GDS-S states, "Do you feel you have more problems with your memory than most?" Analysis of this question along with concomitant GDS-S scores and Water intake, were examined.

In the Lifestyle Questionnaire of the MEDISAustralia Study, eight questions were asked regarding bowel habits, starting with whether the participant was constipated, if so, in what manner was the problem 
Table 1

Origin and Anthropometric Data of Participants of the MEDIS-Australia Study ( $\mathrm{n}=141$ )

\begin{tabular}{|c|c|c|c|c|c|c|}
\hline \multirow[t]{2}{*}{ Island of origin } & \multirow[t]{2}{*}{ No. of subjects } & \multicolumn{2}{|c|}{ Gender } & \multirow[t]{2}{*}{ Mean Age (SD) } & \multirow{2}{*}{$\begin{array}{l}\text { Mean Weight } \\
\text { (SD) }\end{array}$} & \multirow{2}{*}{$\begin{array}{l}\text { Mean Height } \\
\text { (SD) }\end{array}$} \\
\hline & & $\mathrm{M}$ & $\mathrm{F}$ & & & \\
\hline Crete & 52 & 29 & 23 & $73(4.9)$ & $80.8(11.03)$ & $1.6(0.09)$ \\
\hline Cyprus & 74 & 31 & 43 & $75(7.8)$ & $76.3(13.8)$ & $1.6(0.07)$ \\
\hline Limnos & 6 & 2 & 4 & $76(5.2)$ & 76.8 (7.5) & $1.6(0.06)$ \\
\hline Other islands* & 7 & 2 & 5 & $73(8.4)$ & $73.5(12.02)$ & $1.6(0.11)$ \\
\hline TOTALS & 139 & 65 & 76 & $74.25(6.6)$ & 76.9 (11.08) & $1.6(0.08)$ \\
\hline
\end{tabular}

*Other islands includes Corfu, Ithaki, Mitilini, Samos and one from mainland Greece

Table 2

Formulas for Water Intake Estimates (WIE), independent of age

\begin{tabular}{lll}
\hline CODE & Formula & Source \\
\hline WIE1 & $1 \mathrm{~mL} / \mathrm{kcal}$ energy consumed & $\begin{array}{l}\text { National research Council and Subcommittee on the Tenth } \\
\text { Edition of the RDAs, Eds. (1989). Recommended Dietary } \\
\text { Allowances. Washington, DC, The National Academies } \\
\text { Press. }\end{array}$ \\
WIE2 & $\begin{array}{l}\text { 30mL } / \mathrm{kg} \text { body weight (minimum of 1500mL/ } \\
\text { day) }\end{array}$ & $\begin{array}{l}\text { Chernoff, R. (1994). «Meeting the nutritional needs of the } \\
\text { elderly in the institutional setting.» Nutr Rev 52(4): 132- } \\
136 .\end{array}$ \\
$\begin{array}{ll}100 \mathrm{~mL} / \mathrm{kg} \text { for first } 10 \mathrm{~kg}, 50 \mathrm{~mL} / \mathrm{kg} \text { for next } \\
\text { WIE3 }\end{array}$ & $\begin{array}{l}\text { Skipper, A. (1989) Dietitian's handbook of enteral and } \\
\text { parenteral nutrition. Rockville, MD: Aspen Publishers }\end{array}$ \\
\hline
\end{tabular}

addressed and whether there was a familial history. Constipation was self-reported rather than diagnosed.

Additionally, an examination of water requirement was undertaken to determine what quantity of water would be required to ensure individuals were receiving enough to maintain adequate hydration. Initial calculations regarding water content of foods and beverages were undertaken using the NUTTAB 2013 and AUSNUT 2007 databases, processed through FoodWorks 7.0 Professional software. All statistical analysis was undertaken using IBM SPSS Statistics version 22. Analyses were adjusted for covariates, such as specific diuretics and medications that induced a diuretic action using multivariate linear regression and non-parametric analysis.

Normal water loss can occur through five different mechanisms, sweat, urine and faeces, insensible water loss and normal respiration (26). This water loss is influenced by activity, metabolic rate, ambient temperature and humidity. To reasonably estimate water loss and hence water requirements in individuals, these factors need consideration. Firstly, MEDISAustralia participant's activity was minimal with most participants reporting particularly sedentary lifestyles. Consequently, no adjustment was required for activity.
Secondly, according to data received from the Bureau of Meteorology Australia, the mean temperature across the study timeframe from March 2012 through to March 2014 was $16.1^{\circ} \mathrm{C}( \pm 0.22)$ with a mean humidity of $64 \%$ $( \pm 3.4)$ on those days and months when the interviews took place (35). Thirdly, it is assumed that the metabolic production of water is offset by respiratory water loss.

Given the above factors a novel approach may be considered for estimating water requirements, for MEDIS-Australia participants using a formula. Three formulas were proposed by Bossingham, et al, (36), which are outlined in Table 2, along with their primary reference sources.

WIE1 relies on energy intake while WIE2 and WIE3 rely on body weight. WIE1 has been used often since 1945 when first published in the Recommended Dietary Allowances. The recommendation is applied as a footnote to the Recommended Dietary Allowances table and there is no further reference for this recommendation (37). WIE2 also does not supply any further reference, but states, "The fluid requirements for older adults is usually calculated as $30 \mathrm{~mL} / \mathrm{kg}$ body weight with a minimum requirement of $1500 \mathrm{~mL} /$ day". Skipper, the reference for WIE3, references the Manual of Pediatric Nutrition, by Kerner, (1983). 
Table 3

Descriptive statistics of Water Intake Estimates (WIE) $(\mathrm{n}=141)^{*}$

\begin{tabular}{llllll}
\hline & Mean (SEM) & Median (SD) & \multicolumn{2}{l}{$\begin{array}{l}\text { Skewness (SE } \\
\mathbf{0 . 2 0 4})\end{array}$} & \multicolumn{2}{c}{ Kurtosis (SE 0.406) } & 95\% CI for Mean \\
\hline WIE1 & $2477(58.2)$ & $2356(690.5)$ & 1.399 & 4.91 & $(2362.1,2592.1)$ \\
WIE2 & $2335(32)$ & $2319(379.1)$ & 0.17 & -0.255 & $(2272.2,2398.9)$ \\
WIE3 & $2368(16)$ & $2360(189.6)$ & 0.17 & -0.255 & $(2336.1,2399.2)$ \\
\hline
\end{tabular}

*Water intake estimate Mean and Median in $\mathrm{mL}$.

Table 4

Mean and standard error (SEM) for water intake measured against GDS-S score and responses to the question, "Do you feel you have more problems with your memory than others?" (n=139)

\begin{tabular}{|c|c|c|c|c|c|c|c|c|c|c|}
\hline & \multicolumn{2}{|c|}{$\begin{array}{l}\text { Memory Score } \\
\quad(p<0.001)\end{array}$} & \multicolumn{2}{|c|}{$\begin{array}{l}\text { *Total water }(\mathrm{mL}) \\
\quad(\mathrm{p}=0.010)\end{array}$} & \multicolumn{2}{|c|}{$\begin{array}{c}{ }^{* *} \text { Water in food }(\mathrm{mL})(\mathrm{p}= \\
0.014)\end{array}$} & \multicolumn{2}{|c|}{$\begin{array}{l}\text { §Water in beverages }(\mathrm{mL}) \\
\qquad(\mathrm{p}<0.001)\end{array}$} & \multicolumn{2}{|c|}{$\begin{array}{c}\text { | | Plain water }(\mathrm{mL})(\mathrm{p}= \\
0.001)\end{array}$} \\
\hline & & & $\begin{array}{l}\text { Mean } \\
\text { (SEM) }\end{array}$ & $\begin{array}{l}\text { Mean } \\
\text { (SEM) }\end{array}$ & $\begin{array}{l}\text { Mean } \\
\text { (SEM) }\end{array}$ & $\begin{array}{l}\text { Mean } \\
\text { (SEM) }\end{array}$ & $\begin{array}{l}\text { Mean } \\
\text { (SEM) }\end{array}$ & $\begin{array}{l}\text { Mean } \\
\text { (SEM) }\end{array}$ & $\begin{array}{l}\text { Mean } \\
\text { (SEM) }\end{array}$ & $\begin{array}{l}\text { Mean } \\
\text { (SEM) }\end{array}$ \\
\hline \multirow[t]{2}{*}{ All participants } & Yes & 27 & $2871(72.9)$ & $3140(132.8)$ & $1048(36.6)$ & $1202(101.4)$ & $876(36.7)$ & 955 (92.9) & 947 (42.8) & 984 (90.9) \\
\hline & No & 112 & & $2805(83.8)$ & & $1010(37.7)$ & & $857(39.8)$ & & $938(48.5)$ \\
\hline \multirow[t]{2}{*}{ GDS-S $(0-5)(n=39)$} & Yes & 2 & $2800(136.5)$ & $3276(488.4)$ & $1051(51.7)$ & $1099(72.8)$ & $778(60.5)$ & $640(77.9)$ & $971(80.8)$ & $1538(337.5)$ \\
\hline & No & 37 & & $2774(141.5)$ & & $1049(54.5)$ & & $785(63.5)$ & & $941(81.1)$ \\
\hline \multirow[t]{2}{*}{ GDS-S (6-9) $(n=88)$} & Yes & 20 & $2900(96.0)$ & $3133(167.4)$ & 1052 (51.6) & $1240(130.5)$ & $921(48.2)$ & $974(108.1)$ & $927(54.6)$ & $919(91.3)$ \\
\hline & No & 68 & & $2832(113.4)$ & & $997(53.4)$ & & $905(54.0)$ & & $930(65.7)$ \\
\hline \multirow[t]{2}{*}{ GDS-S $(10-13)(n=12)$} & Yes & 5 & $2883(166.9)$ & 3118 (246.6) & $1001(101.0)$ & 1089 (176.3) & $872(128.1)$ & $1004(262.9)$ & $1010(136.3)$ & 1025 (291.5) \\
\hline & No & 7 & & 2715 (217.4) & & 937 (125.2) & & 777 (122.9) & & $1000(133.6)$ \\
\hline
\end{tabular}

${ }^{*}$ Water calculated from all sources, both food and beverages; ${ }^{*}$ Water found only in foods not considered beverages consisting of $45.2 \%$ vegetables, $20.5 \%$ fruit, $19.6 \%$

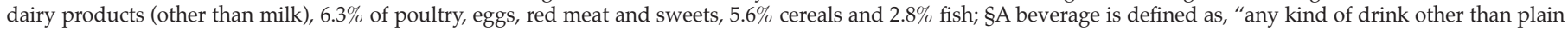

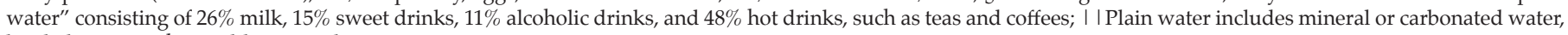
bottled water with no additives and tap water

Table 3 indicates that both skewness and kurtosis suggest that WIE2 or WIE3 would be suitable as a method of estimation. Skewness and kurtosis approached zero at 0.17 and -0.255 respectively, compared to WIE1, which had a skewness of 1.399 and kurtosis of 4.91. As the Confidence Interval for WIE2 had a greater range than that of WIE3, we chose WIE3 as our formula for estimating water intake.

Each participant completed an extensive semiquantitative food frequency questionnaire (MEDIS-FFQ) comprising food frequency and portion size questions for 112 different foods. Portion sizes were determined using images developed for the Australian Guide to Healthy Eating (38), for estimation of food portion sizes. Each food was analysed for water content using the Australian Food, Supplement and Nutrient Database and FoodWorks Professional 7.0. Lifestyle profiles were developed using the MEDIS-LQ, which incorporated the GDS-S.

\section{Results}

All participants $(n=139)$ completed the GDS-S. Due to the small sample size when dividing by gender, an initial analysis of the data was undertaken. Using a Mann-Whitney U Test, the distribution of Water and the GDS-S range were the same for both males and females. Therefore all participants in the analysis were included.

Further, analysis of the ranges within the GDS-S and the relative consumption of water provides the results as shown in Table 4 . The mean total volume of water from all sources consumed by all participants was 2871 $\mathrm{mL}$ (SEM 72.9). The mean total intake of all water for those considered within the normal range of the GDS-S was $2800 \mathrm{~mL}$ (SEM 136.5). Mean total water intake was not statistically different in mild and moderate to severe depression. When we examine the volume of plain water consumed, for those who scored in the moderate to severe depression range we found that there was a higher mean volume intake of plain water (1010 mL (SEM 136.3)) compared to $947 \mathrm{~mL}$ (SEM 42.8) per day for those who scored as not depressed.

When examining the data in Table 4, it is apparent that the total water consumed in all cases, met or exceeded the volume of water estimated as adequate (in this instance, 2,360 $\mathrm{mL}$ as shown in Table 3). As can be seen, the highest percentage of beverage intake was from teas and coffees at $48 \%$. Despite their caffeine content, it has been shown 
Table 5

Mean and Standard Error (SEM) of Fluid Intakes from Various Sources and Constipation ( $\mathrm{n}=119)$

\begin{tabular}{|c|c|c|c|c|c|c|}
\hline \multirow[b]{2}{*}{ Questions } & & \multirow[b]{2}{*}{ Response } & \multicolumn{4}{|c|}{ Water intake in mL/day (SEM) } \\
\hline & & & $\begin{array}{l}\text { Total water } \\
\text { intake }\end{array}$ & Water in foods & $\begin{array}{l}\text { Water in beve- } \\
\text { rages }\end{array}$ & Plain water \\
\hline & & & $(\mathrm{p}=0.010)$ & $(\mathrm{p}=0.014)$ & $(\mathrm{p}<0.001)$ & $(\mathrm{p}=0.001)$ \\
\hline \multirow[t]{2}{*}{ Do you have constipation? } & Yes & 28 & $2751(161.8)$ & $1050(72.3)$ & $709(58.5)$ & $991(77.3)$ \\
\hline & No & 91 & $2967(92.7)$ & $1097(47.4)$ & $907(48.8)$ & $962(58.6)$ \\
\hline \multirow[t]{3}{*}{ How frequently do you go to the toilet?* } & 1 & 7 & $2296(222.2)$ & $982(212.8)$ & $982(212.8)$ & $661(114.8)$ \\
\hline & 2 & 14 & $2893(175.0)$ & $1016(77.5)$ & $1016(77.5)$ & $1048(116.1)$ \\
\hline & 3 & 52 & 3128 (132.4) & $1205(59.7)$ & $1205(59.7)$ & $1039(72.2)$ \\
\hline
\end{tabular}

*1 = up to 1-2 times per week; 2 = 3-5 times per week, 3 = more than 1 time per day

that habitual consumption of caffeinated beverages, such as teas and coffees diminishes the diuretic action of caffeine (39). As participants indicated they drank caffeinated beverages on a daily basis, the diuretic action of the caffeine would be minimal. A Mann-Whitney $\mathrm{U}$ Test indicated there was no significant difference between the levels of depression and water intake from all sources. The total water intake maintains a relative stability as the GDS-S range increases even though the volume of plain water rises. Despite this rise in plain water intake, it still did not meet or exceed the generally recommended consumption of two litres of water a day. This further suggests that the water consumption is not associated with the participant's state of depression.

Table 4 also shows the relationship between the scores from the GDS-S and the relevant score for Question 10 of the GDS-S, "Do you feel you have more problems with your memory than others?"

When considering the volume of water consumed as noted in Table 4, the volume of total water is consistent across all depressive states. We can argue that in this population sample, different volumes of water intake is not associated with memory problems. The relationships between the score for Question 10, and the overall depression scale scores show that those who answered "No" to the question consumed less water overall and less plain water in particular, than their counterparts who answered "Yes" to Question 10. The only exception is the plain water volume for those who scored between 6 and 9 on the GDS-S. All participants who answered "No" to Question 10, showed a total water intake of $2805 \mathrm{~mL}$ (SEM 83.8) as compared to those who answered "Yes" with a total water intake of $3140 \mathrm{~mL}$ (SEM 132.8). This suggests that consuming less than the recommended two litres of plain water per day is not associated with a negative impact on the mood or mental capabilities of these participants. Although this is the case, it needs to be understood that these responses cannot be seen as definitive without objective verification

One of the more common physical problems attributed to a low water intake is constipation (19). We examined the question posed in the MEDIS LQ asking the participants whether they were constipated or not and how this problem was treated. The results of the questions are shown in Table 5, with relevant water volumes.

Of the total number of participants, 123 answered the questions relating to constipation. Four participants did not provide FFQ data, which left a cohort of 119 for analysis.

Table 5 shows the following results, 28 participants, identified as constipated and consumed less total water (2751 mL (SEM 161.8)) than the 91 participants who did not identify as constipated (2967 mL (SEM 92.7)). Although, those who admitted they were constipated consumed a mean of $1050 \mathrm{~mL}$ (SEM 72.3) of water in the food they ate compared to $1097 \mathrm{~mL}$ (SEM 47.4) in the foods of those who claimed not to be constipated, the group who reported they were not constipated consumed more beverages than the group who claimed to be constipated (approximately $200 \mathrm{~mL}$ more). Overall when the totals of food water and beverage water are combined, those who claimed to be constipated consumed a combined mean of water in these two categories of $245 \mathrm{~mL}$ less than those who claimed not to be constipated. Both groups consumed approximately the same volume of plain water, slightly less for those who claimed not to be constipated (991 mL (SEM 77.3) compared to $962 \mathrm{~mL}$ (SEM 58.6)). For the question, "How frequently do you go to the toilet?" the group with the highest frequency of bowel movements (Group 3) consumed the highest total water volume $(3128 \mathrm{~mL}$ (SEM 132.4)). However, this group did not consume the highest volume of plain water, which was attributed to Group 2 (1048 mL (SEM 116.1)). The lowest mean of total water intake (2296 mL (SEM 222.2)) was attributed to Group 1, which has the least frequent bowel motions. Additionally, Group 3 had a higher volume of water from food than Group 1 (a difference of $223 \mathrm{~mL}$ ). Further, when testing for model effects, the level of activity and the taking of diuretic medications did not influence the outcome in any significant way. Another important observation is that the difference in water intake between those who claimed to be constipated and those in Group 3 was highest in 
the water in foods category. As fruits and vegetables were highly represented in this category, consuming water through foods would also add fibre and nutrients which could in part influence bowel habits. All groups who self-reported bowel habits fell short of the expected two litres of plain water a day suggesting that normal bowel function within this group of older adults was not compromised by a self-reported volume of plain water significantly below the suggested two litres of water per day.

\section{Discussion and conclusion}

The expectation that an individual needs to consume two litres of plain water in order to maintain good health has been brought into question commencing with the article by Valtin (2002). The evidence for the consumption of two litres of plain water a day has not been forthcoming and on the contrary, a growing body of evidence disputes this claim $(1,3)$. The recommended quantity may be unnecessary, and unrealistic.

Depression is defined as a serious medical illness characterised by deep feelings of sadness and loss of interest or pleasure in activities (33). Mild cognitive impairment (MCI) is, "....a syndrome defined as cognitive decline greater than that expected for an individual's age and education level but that does not interfere notably with activities of daily life" (9). Identification of MCI is either from the individual concerned or a knowledgeable informant. In this study, we were able to examine self-reported memory difficulties using the GDS-S questionnaire.

The possible association examined between that of depression, memory problems and water intake suggested that those who scored high in the GDS-S consumed less water from foods overall than all other categories. Also, this group of participants consumed more plain water than the other groups. People that reported not being depressed consumed the highest volume of plain water than other groups when answering "yes" to Question 10. This group of participants had a similar consumption of water in foods with the group who tested as moderately depressed, but was lowest for beverages other than water.

There appeared to be an apparent association between the ingestion of water, both as part of foods and beverages and as plain water, with constipation, namely those reporting higher water intake (through food and plain water) were less likely to be constipated. Although this association was evident, the volume of plain water per day was significantly lower than two litres. As these participants scored moderate to high with a Mediterranean diet pattern score and the Mediterranean diet is known to by high in vegetables and fruit, a high volume of water intake from these foods will likely have a concomitant high quantity of fibre. One limitation of this study was the need to compare fibre intake alongside that of water intake. This small crosssectional study suggests that this group of older GreekAustralian migrants do not appear to be affected by lower than recommended water intakes.

Our study results support the view that communityliving older persons have a low likelihood of hypohydration based on adequate water intake from foods. Further there may be other factors for consideration in this regard, such as cultural and communal behaviours that may influence food and water consumption.

The adequate intake of water has been an elusive standard and can be difficult to quantify due to factors such as environment and activity level. In our investigation older Greek-Australians consumed adequate water to meet their estimated water requirement, suggesting that the formula we used to calculate water needs may be useful. However, there are a number of confounders that should be considered. The ambient temperature and humidity are relevant in the estimation of water requirement using a predictive formula, particularly when estimating for physical activity. In this study participants were older and led very sedentary lifestyles.

As our investigation has indicated, a high intake of fresh fruits and vegetables will contribute to the overall water intake. The recommended five vegetables and three fruit portions a day are a suitable target to assist in meeting fluid requirements. This will not only provide water in a plant medium, but also fibre and other nutrients favourable for optimum health. The Mediterranean diet pattern is high in plant-based foods with a high water content. This pattern of eating ensures that community-living older persons may not be at risk of an inadequate water intake when following the Mediterranean diet pattern.

This investigation derived data from the MEDISAustralia study, which was not specifically designed to capture water intake. The nature of this cross-sectional study cannot show a causal relationship between the consumption of water and health outcomes. Also, the intake of other nutrients known to influence bowel habits, such as fibre were not specifically measured and given that the participants ate a diet quite high in fruit and vegetables, this limitation may be significant.

As there appears an association between water intakes, both in the form of foods as well as plain water, more research in this area may shed further light on the possible underlying relationship between health and water consumption. The only effective way to determine this relationship would be with a longitudinal study, possibly by follow-up of the existing MEDIS-Australia participants. The information derived from the MEDISAustralia study was comprehensive and provided insight into the eating and lifestyle behaviours of a group of immigrants to Australia. Research into other ethnic groups and already established Anglo-Celtic Australians 
would further provide insight into how significantly eating and lifestyle behaviours determine water intake and subsequently health.

Ethical Standards: This study was reviewed and approved by the La Trobe University Human Research and Ethics Committee and assigned the Approval number: HEC11-045 in accordance with the National Health and Medical Research Council of Australia's National Statement on Ethical Conduct in Human Research (2007)

\section{References}

1. Race K. 'Frequent Sipping': Bottled Water, the Will to Health and the Subject of Hydration. Body \& Society. 2012;18(3-4):72-98.

2. Masento NA, Golightly M, Field DT, Butler LT, Van Reekum CM. Effects of hydration status on cognitive performance and mood. British Journal of Nutrition. 2014;111(10):1841-52.

3. Marcussen H, Holm PE, Hansen HCB. Composition, Flavor, Chemical Foodsafety, and Consumer Preferences of Bottled Water. Comprehensive Reviews in Food Science and Food Safety. 2013;12(4):333-52.

4. Noakes TD, Adams BA, Myburgh KH, Greeff C, Lotz T, Nathan M. The danger of an inadequate water intake during prolonged exercise. A novel concept re-visited. Eur J Appl Physiol Occup Physiol. 1988;57(2):210-9.

5. Phillips PA, Rolls BJ, Ledingham JG, Forsling ML, Morton JJ, Crowe MJ, et al. Reduced thirst after water deprivation in healthy elderly men. N Engl J Med. 1984;311(12):753-9.

6. Cowen LE, Hodak SP, Verbalis JG. Age-associated abnormalities of water homeostasis. Endocrinology and metabolism clinics of North America. 2013;42(2):349-70.

7. Chan J, Knutsen SF, Blix GG, Lee JW, Fraser GE. Water, Other Fluids, and Fatal Coronary Heart Disease: The Adventist Health Study. American Journal of Epidemiology. 2002;155(9):827-33.

8. Rolls BJ, Phillips PA. Aging and disturbances of thirst and fluid balance. Nutr Rev. 1990;48(3):137-44.

9. Gauthier S, Reisberg B, Zaudig M, Petersen RC, Ritchie K, Broich K, et al. Mild cognitive impairment. The Lancet. 2006;367(9518):1262-70.

10. Wang PN, Wang SJ, Fuh JL, Teng EL, Liu CY, Lin $\mathrm{CH}$, et al. Subjective memory complaint in relation to cognitive performance and depression: a longitudinal study of a rural Chinese population. J Am Geriatr Soc. 2000;48(3):295-9.

11. Popkin BM, D'Anci KE, Rosenberg IH. Water, hydration, and health. Nutr Rev. 2010;68(8):439-58.

12. Lieberman HR. Hydration and cognition: a critical review and recommendations for future research. J Am Coll Nutr. 2007;26(5 Suppl):555S$61 S$.

13. Armstrong LE, Ganio MS, Casa DJ, Lee EC, McDermott BP, Klau JF, et al. Mild Dehydration Affects Mood in Healthy Young Women. The Journal of Nutrition. 2012;142(2):382-8.

14. Gopinathan PM, Pichan G, Sharma VM. Role of dehydration in heat stress-induced variations in mental performance. Arch Environ Health. 1988;43(1):15-7.

15. Ganio MS, Armstrong LE, Casa DJ, McDermott BP, Lee EC, Yamamoto LM, et al. Mild dehydration impairs cognitive performance and mood of men. British Journal of Nutrition. 2011;106(10):1535-43.

16. Szinnai G, Schachinger H, Arnaud MJ, Linder L, Keller U. Effect of water deprivation on cognitive-motor performance in healthy men and women. Am J Physiol Regul Integr Comp Physiol. 2005;289(1):R275-80.

17. Shirreffs SM, Merson SJ, Fraser SM, Archer DT. The effects of fluid restriction on hydration status and subjective feelings in man. Br J Nutr. 2004;91(6):951-
8.

18. Féart C, Samieri C, Allès B, Barberger-Gateau P. Potential benefits of adherence to the Mediterranean diet on cognitive health. Proceedings of the Nutrition Society. 2013;72(01):140-52.

19. Arnaud MJ. Mild dehydration: A risk factor of constipation? Eur J Clin Nutr. 2003;57(S2)

20. Beetz R. Mild dehydration: A risk factor of urinary tract infection? Eur J Clin Nutr. 2003;57(S2)

21. Bosshard W, Dreher R, Schnegg JF, Büla CJ. The treatment of chronic constipation in elderly people: An update. Drugs and Aging. 2004;21(14):91130 .

22. Bell EF, Acarregui MJ. Restricted versus liberal water intake for preventing morbidity and mortality in preterm infants. Cochrane Database Syst Rev. 2001(3):CD000503.

23. Montenegro-Bethancourt G, Vossenaar M, Doak CM, Solomons NW. Total daily water intake in Guatemalan children. Food Nutr Bull. 2009;30(4):340-50.

24. Gaoua N, Racinais S, Grantham J, El Massioui F. Alterations in cognitive performance during passive hyperthermia are task dependent. International Journal of Hyperthermia. 2011;27(1):1-9.

25. Maughan RJ, Shirreffs SM, Watson P. Exercise, Heat, Hydration and the Brain. J Am Coll Nutr. 2007;26(suppl_5):604S-12.

26. Leiper JB, Carnie A, Maughan RJ. Water turnover rates in sedentary and exercising middle aged men. British Journal of Sports Medicine. 1996;30(1):24-6

27. Weinberg AD, Minaker KL, Coble YD, Davis RM, Head CA, Howe JP et al. Dehydration: Evaluation and management in older adults. JAMA. 1995;274(19):1552-6.

28. ABS. Microdata: Australian Health Survey, National Health Survey, 201112. Canberra, Australia: Australian Bureau of Statistics, 2014 Contract No. 4324.0.55.001.

29. Kouris-Blazos A, Wahlqvist ML. The traditional Greek food pattern and overall survival in elderly people. Aust J Nutr Diet. 1998;55(4 Suppl):S20-S3.

30. Supreme Scientific Health Council. Dietary guidelines for adults in Greece. Ministry of Health and Welfare, 1999 Contract No.: 5.

31. Panagiotakos DB, Polychronopoulos E. Study Protocol: The MEDiterranean Islands Epidemiological Study. 2005.

32. Panagiotakos DB, Pitsavos C, Stefanadis C. Dietary patterns: a Mediterranean diet score and its relation to clinical and biological markers of cardiovascular disease risk. Nutr Metab Cardiovasc Dis. 2006;16(8):559-68.

33. American Psychiatric Association. Diagnostic and Statistical Manual of Mental Disorders 5th Edition DSM-5. 5th ed. Arlington, Virginia, USA: American Psychiatric Publishing; 2013.

34. Wancata J, Alexandrowicz R, Marquart B, Weiss M, Friedrich F. The criterion validity of the Geriatric Depression Scale: a systematic review. Acta Psychiatrica Scandinavica. 2006;114(6):398-410.

35. Bureau of Meteorology. Climate and past weather Canberra, ACT, Australia: Commonwealth of Australia; 2014 [cited 2014 December 10]. Available from: http: / / www.bom.gov.au/climate/.

36. Bossingham MJ, Carnell NS, Campbell WW. Water balance, hydration status, and fat-free mass hydration in younger and older adults. Am J Clin Nutr. 2005;81(6):1342-50.

37. Food and Nutrition Board. Recommended Dietary Allowances, August 1945. Washington D.C.: National Research Council; 1945

38. NHMRC. The Guidelines Canberra, Australia: National Health and Medical Research Council; 2013 [updated 2014; cited 2015 February 22]. Available from: http: / / www.eatforhealth.gov.au/guidelines.

39. Grandjean AC, Reimers KJ, Bannick KE, Haven MC. The Effect of Caffeinated, Non-Caffeinated, Caloric and Non-Caloric Beverages on Hydration. J Am Coll Nutr. 2000;19(5):591-600. 